\title{
"Não caber em si", "Ficar sem pinga de sangue": estudo comparativo de expressões idiomáticas do domínio dos sentimentos no português brasileiro e no português europeu Feeling idioms in Brazilian and European Portuguese: a comparative study
}

\author{
Laís Moreira Nogueira* \\ Diogo Oliveira R. Pinheiro** \\ Maria Lúcia L. de Almeida ${ }^{* * *}$
}

\begin{abstract}
RESUMO: Os sentimentos são universais e inerentes ao ser humano, mas a forma como cada língua ou variante linguística os conceptualiza e lexicaliza é culturalmente situada. A fim de verificar como se dá esse processo de variação intercultural, este trabalho analisa, à luz do paradigma da Linguística Cognitiva, expressões idiomáticas (EIs) do domínio dos sentimentos nas variantes brasileira e europeia do português. Para isso, foram selecionadas, para ambas as variantes, EIs associadas a cinco tipos de sentimentos: amor, raiva/ódio, felicidade/alegria, tristeza e medo. Um teste offline de acessibilidade foi aplicado a falantes nativos das duas variantes, a fim de avaliar as convergências e divergências interpretativas. Verificou-se uma situação de predominante convergência em relação ao reconhecimento e à interpretação das expressões, ao lado de algumas divergências que parecem revelar diferenças significativas no que tange à conceptualização de determinados sentimentos.
\end{abstract}

PALAVRAS-CHAVE: Expressões idiomáticas. Sentimentos. Estudo KEYWORDS: Idioms. Feelings. comparativo. Linguística Cognitiva.

\begin{abstract}
Although feelings are universal and inherent to human nature, their construal and lexicalization are languagespecific. Drawing on cognitive linguistics framework, this paper aims to investigate such a process of intercultural variation by analyzing feeling idioms belonging to both Brazilian Portuguese (BP) and European Portuguese (EP). After selecting idioms expressing five different feelings - love, anger/hate, hapiness/joy, sadness and fear -, we have conducted an offline comprehension experiment with native speakers of both varieties trying to identify interpretive convergences and divergences. The results show a high degree of convergence between $\mathrm{BP}$ and EP regarding the recognition and interpretation of the expression, as well as certain significant divergences, which seem to suggest relevant differences in the conceptualization of specific feelings.
\end{abstract}

\section{Introdução}

Graças à ênfase dada à regularidade gramatical, que motiva a busca por regras e princípios minimamente gerais, os idiomatismos sintáticos e semânticos têm permanecido à

\footnotetext{
${ }^{*}$ Mestra, Faculdade de Letras - UFRJ.

** Professor Doutor, Faculdade de Letras - UFRJ.

${ }^{* * *}$ Professora Doutora, Faculdade de Letras - UFRJ.
} 
margem do interesse da linguística gerativa mainstream. Por outro lado, expressões idiomáticas (EIs) têm estado no centro das investigações de outras linhagens teóricas, como a longa tradição fraseológica europeia (BALLY, 1905; CASARES, 1992 [1950]; GUIRAUD, 1962 [1954]) e, mais recentemente, a Linguística Cognitiva (LC), que emerge nos Estados Unidos nos anos 80 do século passado (LAKOFF, 1987; FILLMORE et al., 1988).

Na seara específica da LC, os usos idiomáticos se converteram em foco de interesse por duas razões distintas e complementares. De um lado, o desenvolvimento da Gramática de Construções foi impulsionado pela constatação de que a abordagem gerativista, baseada no modelo dual léxico mais regras, tinha dificuldade em lidar com as sentenças sintática ou semanticamente irregulares (FILLMORE et alii, 1988). De outro, o interesse pela base experiencial da linguagem e do pensamento e pelos processos cognitivos subjacentes à linguagem figurativa (LAKOFF JOHNSON, 1980; JOHNSON, 1987; LAKOFF, 1987; SWEETSER, 1990; LAKOFF; JOHNSON, 1999), em grande medida tributário do estudo de Reddy (1979) sobre a metáfora do conduto, conduziu naturalmente ao interesse pelos idiomatismos semânticos.

Este trabalho se alinha a essa segunda tradição da Linguística Cognitiva: focalizando expressões semanticamente (mas não sintaticamente) idiomáticas, voltamos-nos para o domínio conceptual dos sentimentos, observando especificamente cinco deles: amor, raiva/ódio, felicidade/alegria, tristeza e medo A abordagem proposta é comparativa e experimental: por meio de um teste offline de acessibilidade lexical, são cotejadas expressões do português brasileiro (PB) e do português europeu (PE), com o objetivo de avaliar as diferenças e semelhanças na conceptualização dos sentimentos contemplados, bem como os processos conceptuais que alicerçam a conceptualização das EIs investigados nas duas variantes.

Com isso, este trabalho busca se somar ao conjunto de estudos desenvolvidos, nos últimos anos, em torno da representação de sentimentos no português. Exemplos recentes são o trabalho de Batoréo (2006), que trata da relação entre Linguagem e Emoção em narrativas produzidas por falantes do PE, a dissertação de Land (2008), que analisa a ocorrência e a frequência de enunciados referentes a emoções ativadas em contexto de terrorismo, e o estudo de Nunes e Teixeira (2012), que descreve os correlatos acústicos da expressão de emoção espontânea no PE. Ao optar por uma abordagem comparativa e com foco sobre as expressões idiomáticas (EIs), o presente artigo pretende fornecer sua contribuição para a compreensão da expressão e conceptualização dos sentimentos no português. 


\section{Fundamentação teórica}

A história da Linguística Cognitiva (LC) se inicia em fins da década de 70 do século passado. É nesse momento que um pequeno grupo de pesquisadores, trabalhando de forma independente, começa a questionar o princípio gerativista da autonomia da forma gramatical. Embora desenvolvidos a partir de interesses teóricos diversos, os trabalhos pioneiros de George Lakoff, Ronald Langacker, Leonard Talmy, Charles Fillmore e Gilles Faucconier compartilham a crença de que a linguagem humana é conceptualmente motivada. Na prática, isso significa que a forma linguística não se encerra nos limites estreitos da própria forma. Em vez disso, ela reflete, em larga medida, habilidades cognitivas gerais (quer dizer, não especificamente linguísticas), como a capacidade de estabelecer relações analógicas entre domínios, categorizar entidades, deslocar o foco de atenção e assumir diferentes pontos de vista, entre muitas outras. Em suma, para citar o slogan apenas aparentemente tautológico de Goldberg (1995, p. 5), a ideia fundamental é a de que "conhecimento linguístico é conhecimento".

$\mathrm{Na}$ medida em que abandona a compreensão da linguagem como sistema formal autônomo e desencarnado, a Linguística Cognitiva representa uma ruptura epistemológica profunda em relação aos paradigmas gerativista e estruturalista. Fundamentalmente, do ponto de vista da LC, a linguagem constitui uma forma de conceptualização da realidade. Isso significa que o significado de uma expressão linguística não se esgota no conteúdo objetivo que ela evoca; a maneira como o conceito é construído pelo sujeito cognitivo é tão relevante quanto o cenário objetivamente descrito.

Ao mesmo tempo, o paradigma tende a enfatizar a centralidade das experiências sensório-motoras, para a cognição humana. Em outras palavras, assume-se que a conceptualização do mundo se funda nas experiências corporais. Dessa ideia, frequentemente referida como a hipótese da corporificação da cognição e da linguagem, decorre o pressuposto de que a linguagem refletiria, em alguma medida, a experiência do corpo no mundo real. Sob essa ótica, o corpo e a mente não serão entendidos, naturalmente, como entidades independentes (LAKOFF; JOHNSON, 1980; JOHNSON, 1987; LAKOFF; JOHNSON, 1999).

Da mesma maneira, a já mencionada hipótese da motivação conceptual da forma gramatical implica a eliminação das fronteiras clássicas entre conhecimento de dicionário e conhecimento enciclopédico. Afinal, se não é possível isolar o sistema linguístico do restante da cognição do sujeito falante, também não é possível demarcar os limites entre o linguístico e 
o não-linguístico. Para além disso, em termos práticos, tentativas anteriores de isolar o suposto núcleo semântico estável do significado revelaram-se infrutíferas (COULSON, FAUCONNIER, 1999; TAYLOR, 2006).

$\mathrm{O}$ restante desta seção se ocupa de duas tarefas. Em primeiro lugar, apresentamos e definimos alguns dos instrumentos teóricos empregados na análise das expressões idiomáticas do PB e do PE. Em particular, discutimos os conceitos de Modelo Cognitivo Idealizado (MCI), Esquema Imagético (EI), Metáfora Conceptual e Metonímia Conceptual. Em seguida, discutimos as propriedades caracterizadoras das expressões idiomáticas, a fim de delimitarmos a unidade de análise deste trabalho.

\subsection{Modelo Cognitivo Idealizado (MCI), Esquema Imagético (EI), Metáfora Conceptual e Metonímia Conceptual e língua como base de conhecimento.}

Para dar conta da análise dos processos semântico-cognitivos envolvidos na conceptualização dos eventos codificados por expressões idiomáticas, este estudo recorre às seguintes categorias de análise: MCI, EI, Metáfora Conceptual e Metonímia Conceptual.

O conceito de MCI foi desenvolvido por Lakoff (1987, p. 68-75) para fazer referência a estruturas de organização do conhecimento associadas a categorias não-aristotélicas e capazes de produzir efeitos prototípicos. O MCI é um todo complexo que se sustenta sobre outras estruturas de conhecimento, como os frames, processos cognitivos (metáfora e metonímia) e EIs $^{1}$.

Os MCIs estão vinculados à significação das palavras dentro de uma construção em que o falante precisa da base cultural para acessar o significado, como no caso clássico do substantivo bachelor em inglês (LAKOFF, 1987, p. 70), cujo significado só pode ser compreendido com base no conhecimento social sobre as expectativas relativas a casamento e à existência de uma idade apropriada para se casar ${ }^{2}$.

Os Esquemas Imagéticos (LAKOFF, 1987; JOHNSON, 1987; LAKOFF e TURNER, 1989) são representações pré-linguísticas, sem conteúdo proposicional. Trata-se de padrões

\footnotetext{
1 “Cada MCI é um todo estruturado complexo, uma gestalt, que usa quatro tipos de princípios estruturadores:

- estruturas proposicionais, como os frames de Fillmore

- estruturas de esquemas de imagem, como na Gramática Cognitiva de Langacker

- mapeamentos metafóricos, tais como descritos por Lakoff e Johnson

- mapeamentos metonímicos, tais como descritos por Lakoff e Johnson" (LAKOFF, 1987, p. 68)

${ }^{2} \mathrm{O}$ exemplo é originalmente de Fillmore (1982), que recorre ao termo "bachelor" para ilustrar o conceito de frame.
} 
abstratos que codificam experiências ancoradas nas experiências corpóreas universais da espécie humana, tais como: nossa cabeça fica acima, os pés nos apoiam, somos capazes de olhar acima e abaixo. Alguns desses padrões abstratos, ou Esquemas Imagéticos, são: CONTÊINER, CAMINHOS, FORÇA, EQUILÍBRIO, CIMA-BAIXO, FRENTRE-COSTAS, PARTE- TODO etc.

Por sua vez, a Teoria da Metáfora Conceptual de Lakoff e Johnson (1980) nos faz entender a metáfora não apenas como recurso poético ou estilístico, mas como um processo cognitivo fundamental para linguagem e pensamento. Geeraerts (2010, p. 204-210) estabelece três pilares para descrever a Metáfora Conceptual.

O primeiro consiste no insight de que a metáfora é um fenômeno cognitivo e não apenas lexical, ou seja, não está situada no nível superficial da linguagem. Na verdade, trata-se de um fenômeno conceptual que está enraizado na forma como pensamos e conceptualizamos a realidade.

O segundo é a ideia de que a metáfora deve ser analisada como um mapeamento entre dois domínios. As metáforas permitem conceptualizar um domínio-alvo em termos de um domínio-fonte, e o mapeamento toma forma na relação entre aspectos da fonte e do alvo.

$\mathrm{O}$ terceiro consiste na ideia de que o significado linguístico está enraizado na experiência: a experiência humana dá forma à linguagem. Não só entendemos um conceito a partir do outro, como também estruturamos conceitos menos concretos e mais vagos em termos de outros mais concretos e bem definidos. Sob essa ótica, o próprio corpo humano é um domínio-fonte particularmente relevante.

A metonímia, assim como a metáfora, é um fenômeno conceptual, e não puramente linguístico. Afinal, metonímias conceptuais nos permitem pensar em um conceito em termos de sua relação com outro conceito contíguo. Outro ponto em comum com as metáforas consiste na sua sistematicidade: as metonímias formam padrões que não se aplicam a apenas um item lexical. Além disso, tais estruturas não se encontram apenas na linguagem, mas na vida em geral, no pensamento e nas atitudes dos usuários da língua, estando ancoradas na experiência (GEERAERTS, 2010, p. 214).

\subsection{Definição e características das EIs}


De acordo com certa tradição de estudos gramaticais (CUNHA; CINTRA, 1985; CÂMARA Jr., 1978), uma expressão idiomática é um conjunto de palavras que transmitem um único significado, no mais das vezes desligado do significado de suas partes constitutivas.

Xatara e colegas (2002) buscam sistematizar essa intuição por meio da seguinte definição: “expressão idiomática é uma lexia complexa indecomponível, conotativa e cristalizada em um idioma pela tradição cultural" (XATARA et alii, 2002, p. 184). Segundo esses autores, para identificarmos uma expressão idiomática, é necessário considerar a

indecomponibilidade da unidade fraseológica (quase não existindo possibilidade de substituição por associações paradigmáticas), a conotação (sua interpretação semântica não pode ser feita com base nos significados individuais de seus elementos) e a cristalização (consagração de um significado estável) (XATARA et alii, 2002, p. 184).

Para Vilela (2002, p. 160), a fraseologia representa as "combinações fixas" de uma língua que podem assumir a função e o significado de palavras individuais (ou lexemas). Teriam, assim, a função de ampliar o léxico, em especial na "área da expressividade”, através de processos de "lexicalização da conceptualização e categorização da nossa experiência quotidiana".

É necessário salientar, de acordo com as definições acima, três características relacionadas às EIs: idiomaticidade (a possibilidade de interpretação de um significado único, que não dependa da interpretação de cada uma das partes constituintes); fixidez (a tendência a uma indecomponibilidade da forma, que impossibilitaria substituições sem perdas semânticas); e cristalização (a consagração do significado através do uso).

O problema das definições de Xatara, Riva e Rios, de um lado, e de Vilela, de outro, é que apresentam características do comportamento de uma parte das EIs como se fosse o comportamento padrão, ou único. Uma solução para parte dessas definições estanques pode ser vista em Fillmore et alii (1988), que propõe a distinção entre expressões de codificação (expressões que podem ser entendidas de maneira composicional) e expressões de decodificação (expressões em que o falante precisa recorrer à idiomaticidade para acessar o significado).

Assim como a idiomaticidade não é característica sine qua non para a interpretação das EIs, também a noção de fixidez não pode ser imediatamente evocada como traço definidor dessas construções. Em primeiro lugar, porque não se trata de um conceito simples. Como 
observa Zuluaga (1980), a "fixidez fraseológica" pode envolver diferentes propriedades: fixidez na ordem dos componentes, fixidez das categorias gramaticais (tempo verbal, gênero, número...), fixidez do inventário dos componentes (impossibilidade de suprimir ou incluir elementos) e fixidez transformacional ("carta blanca" /"la blancura de la carta"). Além disso, trata-se de uma medida relativa: se existem de fato EIs totalmente invariáveis, há também aquelas que podem sofrer variações, sejam elas fonéticas, léxicas, sintáticas ou semânticas (SUÁREZ CUADROS, 2006, p. 77).

Por fim, a cristalização se apresenta, de fato, como uma característica geral das EIs. Esse critério está relacionado à convencionalidade das expressões, ou seja, a consagração através do uso que é comum a todas as expressões independentemente da sua forma, grau de preenchimento/fixidez etc.

Após essa breve discussão sobre a definição e características das EIs, é preciso salientar que, para fins deste estudo, uma característica tomada como crucial das é o fato de as EIs serem consideradas como pertencentes à herança linguística e cultural de um povo, na medida em que cristalizam na língua experiências e maneiras de ver o mundo.

De acordo com Fillmore et alii (1988), além de as Els serem classificadas em expressões de codificação/decodificação, também podem/ser divididas em gramaticais ou extragramaticais, de um lado, e substantivas ou formais, de outro.

No presente trabalho, trataremos de expressões tanto de codificação quanto de decodificação. Além disso, focalizamos tão-somente as EIs gramaticais, ou seja, aquelas que obedecem às regras usuais da gramática do português, sem exibirem estrutura sintática idiossincrática. Por fim, limitamo-nos, ainda, às EIs substantivas, vale dizer, àquelas que preenchem todas as posições previstas na estrutura sintática, sem apresentarem slots abertos.

Finalmente, é necessário salientar, na esteira de Kövecses (2010), que um idiomatismo não é apenas uma expressão com significado especial em relação aos significados de suas partes constituintes; é preciso acrescentar que ele surge a partir de nosso conhecimento mais geral do mundo incorporado em nosso sistema conceptual. Em outras palavras, expressões idiomáticas (ou, pelo menos, a maior parte delas) são, por natureza, conceptuais, e não meramente linguísticas. Tomando como exemplo algumas expressões contendo a palavra "fogo", o autor mostra como outras palavras do mesmo domínio semântico podem aparecer, como "vela", “queimar" etc. Diante disso, ele afirma que é o domínio conceitual de fogo, e não as próprias palavras individuais, que participam no processo de criação de expressões idiomáticas. As 
palavras individuais, portanto, apenas revelam esse processo mais profundo de conceptualização. Em suma, expressões idiomáticas são produtos de nosso sistema conceptual, e não simplesmente uma questão de linguagem.

\section{Metodologia}

\subsection{Visão geral}

O cotejo entre EIs do PB e do PE foi realizado, conforme já ficou dito, por meio de um teste offline de acessibilidade lexical. Os itens abaixo fornecem uma primeira visão geral do experimento:

1) Inicialmente, foram selecionadas EIs correspondentes a cinco sentimentos: amor, raiva/ódio, felicidade/alegria, tristeza e medo. Essas EIs foram retiradas do Dicionário Analógico da Língua Portuguesa (AZEVED0, 2010) e da dissertação de Draguici (2010). Não foi feita uma separação quanto à forma, de maneira que foram utilizadas tanto expressões como "vivaz" (item pertencente à classe dos adjetivos) quanto "levantar o espírito" (padrão sintático verboobjeto).

2) Em seguida, foi conduzido um teste de acessibilidade lexical, com o objetivo de verificar o reconhecimento de diferentes EIs por parte dos falantes do PB e do PE, bem como os significados que eles poderiam construir a partir delas (ver desenho do experimento na seção 3.3).

3) Por fim, os resultados foram analisados de duas maneiras: por meio de uma análise quantitativa, a fim de aferir o grau de reconhecimento da expressão idiomática (ver, na seção 3.5, as categorias utilizadas para fins de classificação das respostas); e, no caso das respostas em que houve interpretação convergente entre os participantes porém desviante do sentido convencional da EI, também por meio de uma análise qualitativa, com vistas a reconstruir os processos cognitivos que levaram à interpretação construída. Neste trabalho, focalizamos em particular esta segunda análise, como se verá na seção 4 .

\subsection{Participantes}

Os testes foram aplicados a nove informantes do PB e nove do PE, de ambos os sexos e com diferentes ocupações. Os informantes foram divididos em grupos iguais de acordo com a faixa etária: 18 a 30 anos, 31 a 60 anos e mais de 60 anos. A divisão da faixa etária tinha como intuito verificar uma possível influência geracional no reconhecimento das expressões. $\mathrm{O}$ recorte em relação à escolaridade foi o nível universitário. 


\subsection{Desenho do experimento}

Para os testes de acessibilidade, foram selecionadas, a partir das fontes indicadas acima, cinco EIs para cada sentimento (amor, raiva/ódio, felicidade/alegria, tristeza e medo) e cada variante (PB e PE), totalizando 25 EIs do PB e 25 EIs do PE (conforme anexo 1). Para a escolha das expressões, adotou-se, como critério, que deveria haver tanto expressões (presumivelmente) reconhecíveis quanto expressões (presumivelmente) opacas para falantes do PB.

\subsection{Tarefa}

Foi pedido aos informantes que fizessem uma paráfrase de cada uma das expressões e que o fizessem da forma mais espontânea possível, sem interromper a tarefa para analisar as respostas e sem alterá-las posteriormente. As instruções foram transmitidas oralmente antes da entrega da folha do teste (anexo 2). A tarefa requerida se prestava a dois objetivos: de um lado, verificar o reconhecimento ou não reconhecimento de cada EI por parte dos falantes nativos de cada variante; de outro, compreender os processos de construção do significado que levam à interpretação das EIs não reconhecidas.

\subsection{Categorias e procedimentos de análise dos resultados}

Conforme já ficou dito (seções 3.1 e 3.4), a análise se dividiu em duas etapas: uma primeira parte quantitativa, que buscou mapear os resultados do teste de acessibilidade, e uma segunda parte qualitativa, que buscou reconstruir os processos de construção de sentido à luz da semântica cognitiva.

Em relação à primeira parte da análise, considerou-se que uma classificação dicotômica das paráfrases fornecidas pelos participantes, do tipo acessou ou não acessou o significado, seria excessivamente simplista e não capturaria plenamente a complexidade do processo de construção de sentidos. Por isso, essas paráfrases foram divididas em quatro classes, a saber.

\section{1) Acessou o significado convencional}

Foram incluídas no primeiro caso as respostas nas quais o informante apresentou a denominação do sentimento tal como retirada do dicionário (ou termo cognato). Por exemplo: se a expressão "ser vivaz" evoca, conforme o significado dicionarizado convencional, ideia de alegria, incluímos no primeiro caso uma paráfrase como "ser alegre". 
2) Acessou significado próximo ao convencional

Foram incluídas no segundo caso as respostas em que o informante se aproximava do significado esperado (sempre conforme o significado convencional do dicionário). Por exemplo: se, para a expressão "Estar aos pés de alguém”, o informante apresenta a paráfrase “estar apaixonado / dominado por alguém", ele se aproximava do significado esperado, mas não utilizava exatamente a palavra que denomina o sentimento.

3) Não acessou o significado convencional

Foram incluídas no terceiro caso as respostas em branco ou respostas nas quais o significado apresentado não era alcançado, nem mesmo como aproximação, e tampouco era compartilhado com outros informantes (o que sugere não se tratar de uma tendência para uma mudança na interpretação da expressão).

\section{4) Alterou o significado}

Finalmente, foram incluídas no quarto caso as respostas em que a paráfrase apresentada não alcançava o significado esperado, mas, tal interpretação era compartilhada por outros informantes. Foi o que ocorreu, por exemplo, com a expressão "Sacudir a poeira", em que diferentes interpretações estiveram associadas à ideia de superar uma dificuldade e não ao sentimento dicionarizado de alegria.

A partir da divisão descrita acima, e para fins operacionais, foram consideradas reconhecidas pelos falantes as expressões que se enquadravam nos grupos 1 e 2 ; inversamente, as expressões que se enquadravam nos grupos 3 e 4 foram consideradas não reconhecidas.

Á luz dessa classificação, foi possível obter um panorama que conduziu à segunda parte da análise: a verificação das bases de conhecimento e processos cognitivos recrutados para a construção do sentido. Para essa etapa, interessavam as respostas enquadradas nas categorias 3 e 4 .

No intuito de identificar os mecanismos cognitivos subjacentes na interpretação das expressões, recorreu-se ao instrumental teórico-analítico da Linguística Cognitiva, em particular os conceitos de esquema imagético (JOHNSON, 1987; SWEETSER, 1990), metáfora 
conceptual (LAKOFF; JOHNSON, 1980; 1999; LAKOFF, 1987; KOVECSES, 2002) e metonímia conceptual (LAKOFF, 1987; RADDEN, 2000; PANTHER; THOENBURG, 2003).

\section{Análise dos resultados}

Iniciamos a apresentação dos resultados pela etapa da análise quantitativa (cf. Metodologia). Os gráficos abaixo apresentam um panorama quantitativo geral de acessibilidade das EIs das duas variantes do português investigadas, segundo falantes nativos do PE e do PB.

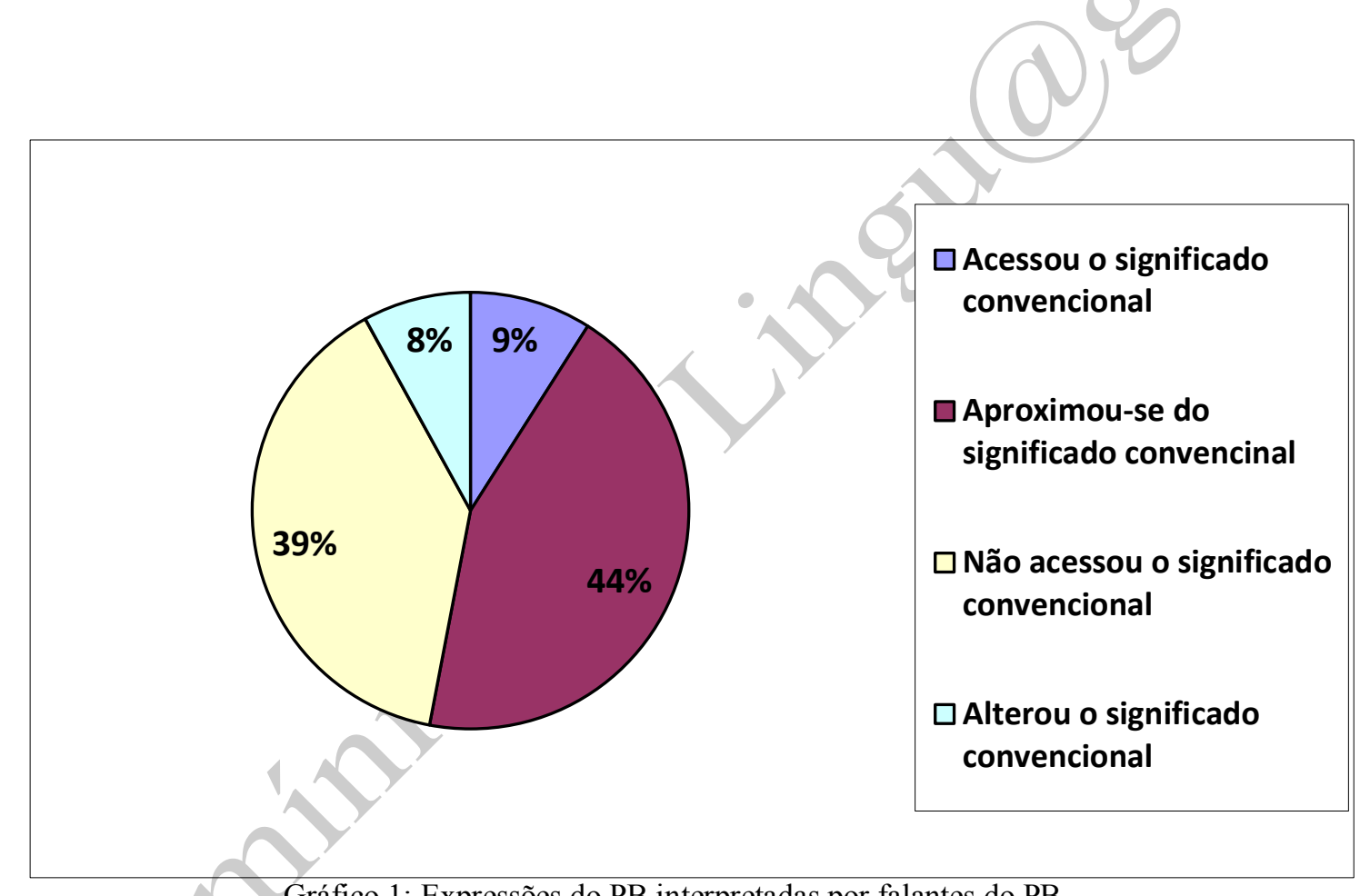

Gráfico 1: Expressões do PB interpretadas por falantes do PB 


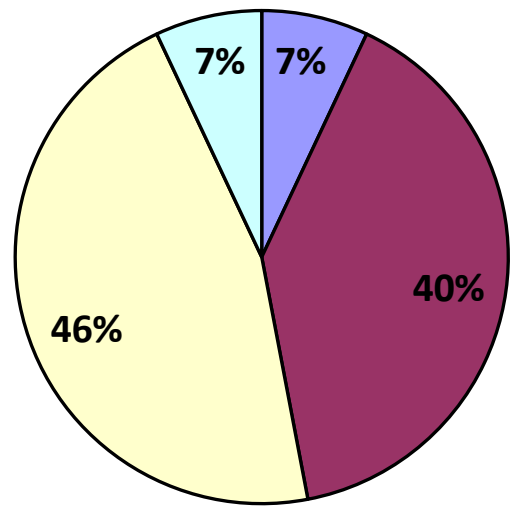

$\square$ Acessou o significado convencional

$\square$ Aproximou-se do significado convencional

$\square$ Não acessou o significado convencional

$\square$ Alterou o significado convencional

Gráfico 2: Expressões do PB interpretadas por falantes do PE

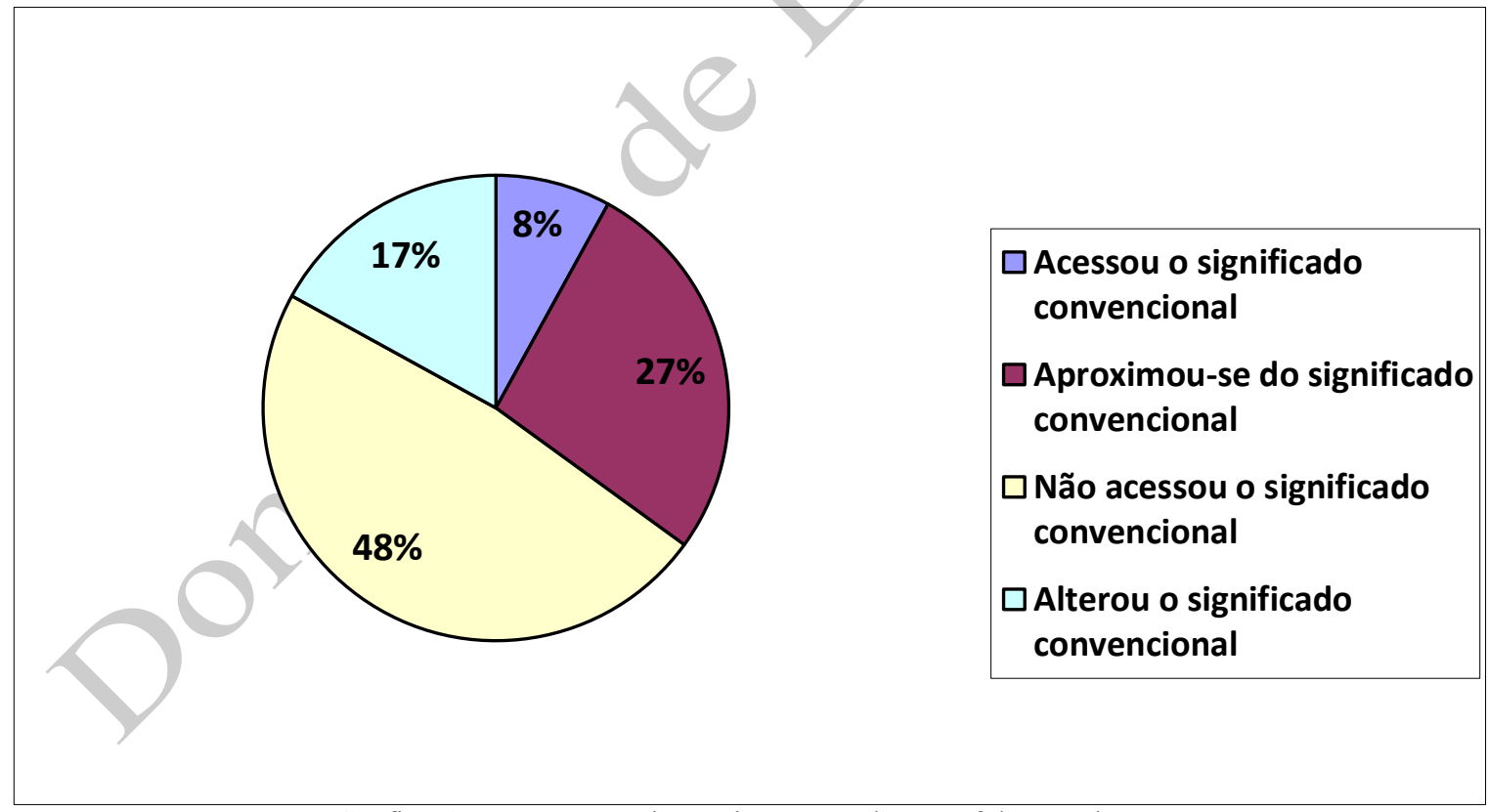

Gráfico 3: Expressões do PE interpretadas por falantes do PE 


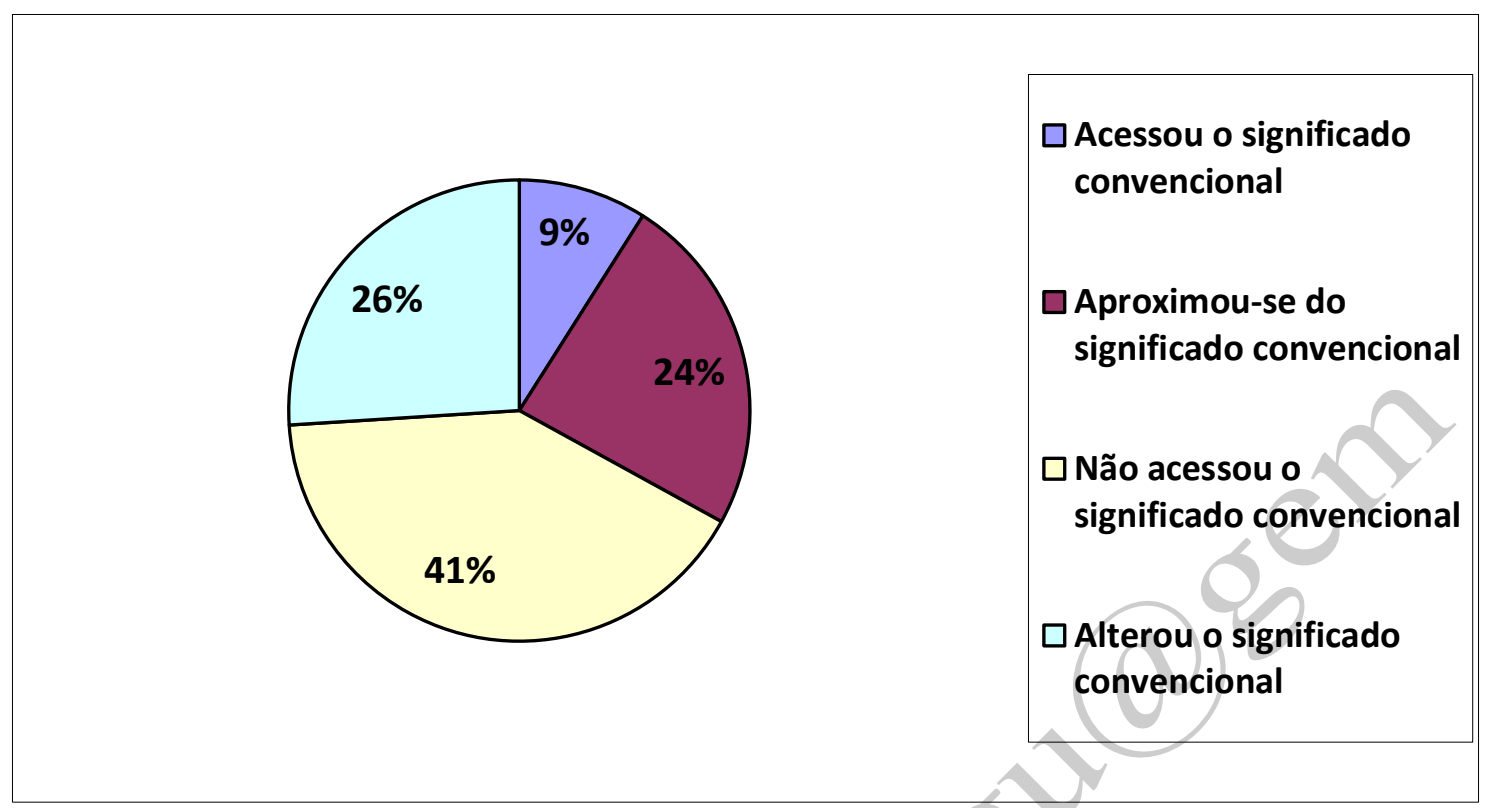

Gráfico 4: Expressões do PE interpretadas por falantes do PB

Como se pode verificar, existe mais convergência do que divergência em relação à acessibilidade das expressões nas variantes estudadas. Por exemplo, considerando-se as expressões idiomáticas do PB, o nível de reconhecimento foi de 53\% para os falantes brasileiros e apenas um pouco inferior, $47 \%$, para os falantes portugueses ${ }^{3}$. Em relação aos EIs do PE, $35 \%$ delas foram reconhecidas por falantes portugueses e $33 \%$ pelos falantes brasileiros.

Certamente, uma investigação das motivações culturais por trás dessa diferença seria da máxima relevância. Como já ficou dito, no entanto, para os propósitos deste estudo, o interesse central recai sobre os casos específicos que apresentaram diferença em relação ao reconhecimento, ou seja, as EIs que se enquadraram nas classes de expressões reconhecidas (1 e 2) para os falantes de uma nacionalidade e não reconhecidas (3 e 4) para os falantes da outra nacionalidade.

Dito isso, passamos a focalizar aqui as diferenças entre as variantes estudadas, observando, especificamente, as expressões que apresentaram diferenças quanto à acessibilidade. Para isso, isolamos, nas próximas sub-seções, as EIs cujo significado foi considerado acessado em uma variante e não acessado em outra (cf. Metodologia).

\footnotetext{
${ }^{3}$ Lembramos que as EIs enquadradas nos grupos "Acessou o significado convencional" e "Aproximou-se do significado convencional" são consideradas reconhecidas, ao passo que as EIs que se enquadram nos grupos "Não acessou o significado" ou "Alterou o significado" são consideradas não reconhecidas.
} 


\subsection{Expressões do PE não reconhecidas por falantes do PB}

Das dez expressões do PE consideradas reconhecidas por falantes portugueses, oito também foram consideradas reconhecidas por falantes brasileiros, a saber:

2. Ferver-lhe o sangue na cabeça

11. Comer alguém com os olhos

9. Ter os nervos à flor da pele

13. Estar louco por alguém

15. Ter um fraco por alguém

17. Levar alguém no coração

18. Arrepiarem-se os cabelos

20. Esfregar as mãos de contente

Aqui, detemo-nos sobre as duas EIs que apresentaram diferença no reconhecimento; a saber:

3. Ficar sem pinga de sangue 21. Não caber em si

As tabelas abaixo sintetizam os resultados referentes à primeira delas. Por razões de clareza visual, nesta tabela e nas próximas, só estão expressas as respostas dadas. Como são nove informantes para cada variante, as tabelas que apresentam menos de 9 colunas indicam implicitamente o número de respostas em branco.

Tabela 1: Acesso do significado da EI "Ficar sem pinga de sangue" no PE

\begin{tabular}{|l|c|c|c|c|}
\hline \multicolumn{1}{|c|}{ PARÁFRASES } & $\mathbf{1}$ & $\mathbf{2}$ & $\mathbf{3}$ & $\mathbf{4}$ \\
\hline $\begin{array}{l}\text { Assustar-se, ficar surpreendido } \\
\text { por algo desagradável e } \\
\text { inesperado. }\end{array}$ & & $\mathrm{X}$ & & \\
\hline Ficar assustado & & $\mathrm{X}$ & & \\
\hline $\begin{array}{l}\text { Assustar-se muito, ficar, por } \\
\text { vezes, pálido devido a um trágico } \\
\text { acontecimento }\end{array}$ & & $\mathrm{X}$ & & \\
\hline $\begin{array}{l}\text { Ficar muito pálido devido a um } \\
\text { susto }\end{array}$ & & $\mathrm{X}$ & & \\
\hline Levar um susto enorme & & $\mathrm{X}$ & & \\
\hline Ficar muitíssimo assustado & & $\mathrm{X}$ & & \\
\hline Apanhar um grande susto & & $\mathrm{X}$ & & \\
\hline Ficar lívido & & $\mathrm{X}$ & & \\
\hline
\end{tabular}


Tabela 2: Acesso do significado da EI "Ficar sem pinga de sangue" no PB

\begin{tabular}{|l|c|c|c|c|}
\hline \multicolumn{1}{|c|}{ PARÁFRASES } & $\mathbf{1}$ & $\mathbf{2}$ & $\mathbf{3}$ & $\mathbf{4}$ \\
\hline Ficar com medo & $\mathrm{X}$ & & & \\
\hline Ficar pálido, abatido & & $\mathrm{X}$ & & \\
\hline $\begin{array}{l}\text { Ficar lívido, semi } \\
\text { desfalecido }\end{array}$ & & $\mathrm{X}$ & & \\
\hline Cansado & & & & $\mathrm{X}$ \\
\hline
\end{tabular}

Como é possível observar, os falantes do PE se aproximaram mais do significado dicionarizado da expressão: basta notar que muitos informantes brasileiros se abstiveram de apresentar uma paráfrase e que apenas nesse grupo se constatou uma interpretação claramente distanciada do significado original, tendo sido incluída no grupo 4 ("Cansado").

Apenas uma paráfrase do PE baseou-se na interpretação linguística, mais básica ("Ficar lívido"); todas as demais acessaram o significado idiomático ao apresentar "susto" e suas variações nas paráfrases. Já no PB, é interessante notar que o contrário aconteceu: apenas um informante apresentou uma paráfrase que aponta para uma interpretação idiomática ("Ficar com medo"). A grande maioria dos informantes, por outro lado, ou não chegou sequer a construir qualquer hipótese semântica ou buscou utilizar a informação linguística para alcançar o significado. É possível perceber assim que, quando a interpretação é calculada composicionalmente, a partir da informação linguística, nem sempre o significado é acessado, como no caso da paráfrase "Cansado". Trataremos disso em uma próxima análise.

Até este ponto, portanto, foi possível verificar que, para a EI "Ficar sem pinga de sangue", os falantes do PE acessaram de forma efetiva o significado idiomático, enquanto os do PB não foram tão eficientes, não chegando a construir um significado possível ou buscando uma interpretação com base no material linguístico disponível.

No que diz respeito à segunda EI, não reconhecida pelos falantes do $\mathrm{PB}$ de acordo com os critérios estabelecidos para o teste de acessibilidade lexical, "Não caber em si", os resultados podem ser vistos nas duas próximas tabelas.

Tabela 3: Acesso do significado da EI "Não caber em si" no PE

\begin{tabular}{|l|c|c|c|c|}
\hline \multicolumn{1}{|c|}{ PARÁFRASES } & $\mathbf{1}$ & $\mathbf{2}$ & $\mathbf{3}$ & $\mathbf{4}$ \\
\hline Extremamente (feliz) & & $\mathrm{X}$ & & \\
\hline Sentir uma forte emoção, alegria & & $\mathrm{X}$ & & \\
\hline $\begin{array}{l}\text { Não poder conter-se (em geral pela } \\
\text { alegria que se sente) }\end{array}$ & & $\mathrm{X}$ & & \\
\hline Estar muito feliz & & $\mathrm{X}$ & & \\
\hline Ficar muito entusiasmado & & $\mathrm{X}$ & & \\
\hline
\end{tabular}




\begin{tabular}{|l|l|c|c|c|}
\hline $\begin{array}{l}\text { Não caber em si [de contente]: excitação } \\
\text { decorrente de algo agradável e inesperado }\end{array}$ & & $\mathrm{X}$ & & \\
\hline Não ter noção de.. & & & & $\mathrm{X}$ \\
\hline Estar perante algo inacreditável & & & & $\mathrm{X}$ \\
\hline
\end{tabular}

Tabela 4: Acesso do significado da EI "Não caber em si" no PB

\begin{tabular}{|l|c|c|c|c|}
\hline \multicolumn{1}{|c|}{ PARÁFRASES } & $\mathbf{1}$ & $\mathbf{2}$ & $\mathbf{3}$ & $\mathbf{4}$ \\
\hline Muito feliz & $\mathrm{X}$ & & & \\
\hline Felicidade & $\mathrm{X}$ & & & \\
\hline Felicidades & $\mathrm{X}$ & & & \\
\hline Estar muito feliz ou orgulhosa & $\mathrm{X}$ & & & $\mathrm{X}$ \\
\hline Extravasar & & & & $\mathrm{X}$ \\
\hline $\begin{array}{l}\text { Plenitude de alguma qualidade positiva ou } \\
\text { negativa }\end{array}$ & & & & $\mathrm{X}$ \\
\hline Extrapolar & & & & $\mathrm{X}$ \\
\hline Deslumbrada, exibicionista & & & & $\mathrm{X}$ \\
\hline
\end{tabular}

Verificamos que, em Portugal, a expressão "Não caber em si" está fortemente associada à ideia de alegria. Ao mesmo tempo, sua interpretação está associada ao esquema imagético do contêiner (JOHNSON, 1980); não à toa, alegria e felicidade apareceram ou entre parênteses ou como aposto. No Brasil, em contraste, a produtividade dessa EI é sensivelmente menos significativa. De qualquer forma, os falantes das duas variantes compartilham da interpretação pautada pelo esquema imagético do contêiner, que sustenta a metáfora O CORPO É UM CONTENTOR DE EMOÇÕES. Os falantes do PB, porém, apresentaram uma tendência maior para essa interpretação.

\subsection{Expressões do PB não reconhecidas por falantes do PE}

Das dez expressões reconhecidas no Brasil, sete também foram consideradas reconhecidas em Portugal, a saber:

5. Estar com o semblante carregado.

10. Estar vendo tudo negro.

12. Ser louco por alguém.

13. Ficar petrificado.

19. Estar babando por alguém.

21. Não querer ver alguém nem pintado de ouro.

23. Estar com os cabelos arrepiados. 
Foram analisadas as três expressões que apresentaram diferença no reconhecimento, a saber:
1. Ser vivaz. ${ }^{4}$
9. Estar aos pés de alguém.

14. Estar de quatro por alguém.

As tabelas abaixo sintetizam os resultados referentes à primeira expressão.

Tabela 5: Acesso do significado da EI "Ser vivaz" no PB

\begin{tabular}{|l|c|c|c|c|}
\hline \multicolumn{1}{|c|}{ PARÁFRASES } & $\mathbf{1}$ & $\mathbf{2}$ & $\mathbf{3}$ & $\mathbf{4}$ \\
\hline $\begin{array}{l}\text { Ser alegre / movimentado } \\
\text { / agitado }\end{array}$ & $\mathrm{X}$ & & & \\
\hline Esperto, vivo, alegre & $\mathrm{X}$ & & & \\
\hline $\begin{array}{l}\text { Uma pessoa expressiva, } \\
\text { alegre }\end{array}$ & $\mathrm{X}$ & & & \\
\hline Alegre & $\mathrm{X}$ & $\mathrm{X}$ & & \\
\hline $\begin{array}{l}\text { Que tem vivacidade, que } \\
\text { está viva, força, sentido } \\
\text { de energia também }\end{array}$ & & $\mathrm{X}$ & & \\
\hline Cheio de vida & & $\mathrm{X}$ & & \\
\hline Cheio de vida & & & & $\mathrm{X}$ \\
\hline Ser sagaz & & & & \\
\hline
\end{tabular}

Tabela 6: Acesso do significado da EI "Ser vivaz" no PE

\begin{tabular}{|l|c|c|c|c|}
\hline \multicolumn{1}{|c|}{ PARÁFRASES } & $\mathbf{1}$ & $\mathbf{2}$ & $\mathbf{3}$ & $\mathbf{4}$ \\
\hline É alegre & $\mathrm{X}$ & & & \\
\hline Muito alegre, ativo & $\mathrm{X}$ & & & \\
\hline $\begin{array}{l}\text { Cheio de vida, dinâmico, } \\
\text { extrovertido }\end{array}$ & & $\mathrm{X}$ & & $\mathrm{X}$ \\
\hline $\begin{array}{l}\text { Esperto, compreende tudo } \\
\text { rapidamente }\end{array}$ & & & & $\mathrm{X}$ \\
\hline Pessoa calorosa, explosiva & & & & \\
\hline
\end{tabular}

\footnotetext{
${ }^{4}$ No dicionário analógico utilizado como fonte, essa expressão aparece associada ao sentimento de alegria. Entende-se que a expressão não está sendo utilizada de maneira literal; em vez disso, ela envolve um uso metafórico/metonímico de vida como alegria. Por essa razão, é considerada uma expressão idiomática.
} 
Verificamos que, no Brasil, a expressão está mais fortemente associada à ideia de alegria ou vivacidade. Já em Portugal, esse sentido é menos acessível, como se comprova pelo maior número de respostas em branco e pelo fato de que alguns informantes buscaram construir interpretações diversas, conforme mostram as paráfrases com o substantivo "esperteza" e os adjetivos "calorosa" e "explosiva".

Algo semelhante ocorre em relação ao par de EIs "Estar aos pés de alguém" e "Estar de quatro por alguém", como se vê abaixo.

Tabela 7: Acesso do significado da EI "Estar aos pés de alguém" no PB

\begin{tabular}{|c|c|c|c|c|}
\hline PARÁFRASES & 1 & 2 & 3 & 24 \\
\hline Subserviente, amando, apaixonado & $\bar{X}$ & & & \\
\hline Apaixonado/dominado & & $\mathrm{X}$ & & 8 \\
\hline Faz tudo que a pessoa quer & & $\mathrm{X}$ & & \\
\hline Apaixonado, caído & & $\mathrm{X}$ & & \\
\hline $\begin{array}{l}\text { Apaixonado, caidinho, } \\
\text { mandado" }\end{array}$ & & $\mathrm{X}$ & & \\
\hline Faz qualquer coisa pela pessoa & & & & \\
\hline Estar caído & & $X$ & & \\
\hline Faz o que quer com a pessoa & & $\mathrm{X}$ & & \\
\hline
\end{tabular}

Tabela 8: Acesso do significado da EI "Estar aos pés de alguém" no PE

\begin{tabular}{|l|c|c|c|c|}
\hline PARÁFRASES & $\mathbf{1}$ & $\mathbf{2}$ & $\mathbf{3}$ & $\mathbf{4}$ \\
\hline Apaixonado & & $\mathrm{X}$ & & \\
\hline Sob o domínio & & & & $\mathrm{X}$ \\
\hline Encontra-se à mercê & & & & $\mathrm{X}$ \\
\hline Caído por & & $\mathrm{X}$ & & \\
\hline
\end{tabular}

Tabela 9: Acesso do significado da EI "Estar de quatro por alguém" no PB

\begin{tabular}{|l|c|c|c|c|}
\hline PARÁFRASES & $\mathbf{1}$ & $\mathbf{2}$ & $\mathbf{3}$ & $\mathbf{4}$ \\
\hline Apaixonado, faria qualquer coisa & & $\mathrm{X}$ & & \\
\hline Está caído por & & $\mathrm{X}$ & & \\
\hline Completamente apaixonado & & $\mathrm{X}$ & & \\
\hline Apaixonado & & $\mathrm{X}$ & & \\
\hline Apaixonado & & $\mathrm{X}$ & & \\
\hline Apaixonado & & $\mathrm{X}$ & & \\
\hline Apaixonado & & $\mathrm{X}$ & & \\
\hline Apaixonado/Caidinho & $\mathrm{X}$ & & \\
\hline Tá perdido, coitado & & $\mathrm{X}$ & & \\
\hline
\end{tabular}

Tabela 10: Acesso do significado da EI "Estar de quatro por alguém" no PE

\begin{tabular}{|l|l|l|l|l|}
\hline \multicolumn{1}{|c|}{ PARÁFRASES } & $\mathbf{1}$ & $\mathbf{2}$ & $\mathbf{3}$ & $\mathbf{4}$ \\
\hline Apaixonado & & $\mathrm{X}$ & & \\
\hline Apaixonado & & $\mathrm{X}$ & & \\
\hline Está aos pés & & $\mathrm{X}$ & & \\
\hline
\end{tabular}




\begin{tabular}{|l|l|l|l|l|}
\hline Caidinho / apaixonado & $\mathrm{X}$ & & \\
\hline
\end{tabular}

Neste par de expressões (“Estar aos pés de alguém” e "Estar de quatro por alguém”), ao se atentar para a diferença de paráfrases produzidas pelos informantes do PB e do PE, observase uma diferença em relação à produtividade ${ }^{5}$ dessas EIs nas duas variantes. $\mathrm{O}$ fator cultural parece explicar tal diferença, na medida em que o MCI de AMOR, no Brasil, parece incluir um ponto de vista negativo referente à subserviência do ser que ama em relação ao ser amado. A produtividade da expressão e suas paráfrases indicam que, para nós, amar significa também estar preso às vontades do outro, estar em uma relação de inferioridade em relação ao outro, ou seja, "estar perdido, coitado!".

\section{Conclusão}

A questão que motivou o presente estudo foi a seguinte: como se dá a conceptualização dos sentimentos humanos básicos nas variantes brasileira e europeia do português? Para isso, investigamos como falantes de ambas as variantes buscavam construir interpretações para expressões idiomáticas associadas ao domínio dos sentimentos.

À guisa de conclusão, passamos a sintetizar os resultados alcançados:

1) os esquemas imagéticos do CONTÊINER e CIMA BAIXO têm grande participação nas interpretações das EIds.

2) o número de expressões consideradas do PB e o de expressões consideradas PE reconhecidas por falantes europeus foi reduzido em ambas as variantes, o que mostra que os dicionários não são boas fontes para observar as EIds em uso na língua.

De maneira geral, as formas de categorização dos sentimentos nas variantes do PB e do $\mathrm{PE}$ evidenciam que a linguagem reflete capacidades cognitivas gerais do ser humano e que a cultura em que se está inserido tem participação nesse processo. A influência do conhecimento cultural foi observada na análise, dado que as expressões "Estar aos pés de alguém" e "Estar de quatro por alguém" apresentaram considerável diferença de produtividade. Tal resultado foi relacionado a diferenças no MCI em torno do sentimento amor nas duas variantes, tendo na variante do PB um ponto de vista negativo associado a "prisão", "submissão".

\footnotetext{
${ }^{5}$ Neste trabalho, empregamos o termo produtividade em referência à frequência de ocorrência de uma EI.
} 
Assim como é o caso com outras construções gramaticais, o conhecimento idiomático se configura a partir do uso em contextos específicos; fora desse contexto, a significação idiomática é perdida, mas não deixa de ser possível a formação de "imagens mentais ricas". Isso permite que a conceptualização da expressão envolva o aspecto idiomático, mas, eventualmente o transcenda. Exemplos são o slogan "Um filme de arrepiar os cabelos", do filme Enrolados, produzido pela Disney, e a expressão "Sacode a poeira”, que parece ter sofrido um processo de mudança semântica, evoluindo da ideia de alegria para a de superação.

A título de encerramento, pode ser interessante citar as palavras de Batoréo, para quem

a conceptualização das emoções tanto pode ser vista com a motivação fisiológica como com a motivação cultural, tal como mostram ao longo dos anos os estudos de A. Wierzbicka (sobretudo 1992 e 1996) e, ultimamente, D' Andrade (1987) e Geeraerts e Grondelaers (1995). Apesar da aparente contradição entre as duas correntes, a tendência actual é, antes, para tratar as duas perspectivas como complementares (BATORÉO, 2001, p. 449).

Ao fim e ao cabo, foi possível constatar, neste trabalho, a complementaridade entre os processos conceptuais de base corpórea e pretensamente universais, de um lado, e a variação intercultural, associada a representações histórica e geograficamente situadas.

\section{Referências Bibliográficas}

AZEVEDO, F. F. dos S. Dicionário Analógico da Língua Portuguesa: ideias afins/ thesaurus. Lexikon, 2010.

BALLY, C. Précis de stylistique. Esquisse d'une méthode fondée sur l'étude du français moderne. Genebra: Eggimann, 1905. ([1909] 1951): Traité de stylistique française. 2 vol. Paris: Klincksieck.

BATORÉO, H. J. O espaço das emoções no Português Europeu: reflexões metodológicas sobre a poste entre neurociências e linguística cognitiva. In: Linguagem e Cognição: A Perspectiva da Linguística Cognitiva. Org.: Augusto Soares da Silva. Ed.: Associação Portuguesa de Linguística/ Universidade Católica Portuguesa - Faculdade de Filosofia de Braga, 2001.

. Expressão de emoções e discurso: Aspectos de estratégias linguísticas de avaliação em narrativas produzidas por falantes não nativos do Português Europeu. In Textos seleccionados do XXI Encontro Nacional da Associação Portuguesa de Linguística, Lisboa, APL, 2006. 219-230 p.

CAMARA Jr., J. M. Dicionário de Linguística e Gramática. Petrópolis: Vozes, 8ª ed. 1978.

CASARES, J. Introducción a la lexicografía española. Madrid: CSIC, 1992 [1950]. 
CUNHA, C.; CINTRA, F. L. Nova gramática do português contemporâneo. Rio de Janeiro: Nova Fronteira. 1985.

DRAGUICI, C. Expressões idiomáticas na área das emoções em Português e Romeno. Dissertação (Mestrado em Língua e Cultura Portuguesa). Faculdade de Letras, Universidade de Lisboa, 2009.

FAUCCONNIER, M.; COULSON, S. Fake guns and stone lions: conceptual blending and private adjectives. In: FOX, B.; JURAFSKY, D.; MICHAELIS, L. (Eds.) Cognition and Function in Language. Palo Alto, CA: CSLI, 1999.

FILLMORE. C. Frame semantics. In: THE LINGUISTIC SOCIETY OF KOREA (Ed.), Linguistics in the Morning Calm. Seul: Hanshin, 1982. 111-137 p.

. KAY, P., O'CONNOR, M. C. Regularity and idiomaticity in grammatical constructions: the case of let alone. Language, v. 64, 1988.

GEERAERTS, D.; GRONDELAERS, S. Looking back at Anger: Cultural Traditions and Metaphorical Patterns. J. Taylor \& R. E. MacLaury (eds.), Language and the Construal of the World. Berlin/New York: Mouton de Gruyter, 1995.

. Theories of Lexical Semantics. Oxford: Oxford University Press [2010]

GUIRAUD, Pierre. Les locutions françaises. Paris: Presses Universitaires de France, 1962 [1954].

JOHNSON, M. The body in the mind: The bodily basis of meaning, imagination, and reason. Chicago: University of Chicago Press. 1987.

KÖVECS, Z. Metaphor: a practical introduction / Zoltán Kövecses; exercises written with Szilvia Csábi ... [et al.].-2nd ed. 2010.

LAKOFF, G.; JOHNSON, M. Metaphors we live by. Chicago: University Press, 1980.

LAKOFF, G. Women, fire and dangerous things: what categories reveal about the mind. Chicago: Chicago University Press, $1987 . \quad$ crossref http://dx.doi.org/10.7208/chicago/9780226471013.001.0001

; TURNER. More than Cool Reason. A Field Guide to Poetic Methafor, 1989.

; JOHNSON, M. Philosophy in the flesh: the embodied mind and its challenge to western thought. New York: Basic Books, 1999.

; JOHNSON, M. Metáforas da vida Cotidiana. Campinas: Mercado de Letras; São Paulo: Educ, 2002 [1999]. 
LAND, A. I. C. M. Heróis, vilões, vítimas e emoções no discurso jornalístico em relação ao terrorismo: de Nova Iorque a Madrid e Londres. Uma abordagem cognitiva. Dissertação de Mestrado. Lisboa: Universidade Aberta, 2008.

LANGACKER, R. W. Foundations of Cognitive Grammar, Volume I, Theoretical Prerequisites. Stanford, California: Stanford University Press, 1987.

Grammar and Conceptualization. Mouton de Gruyter, New York. 1999. crossref http://dx.doi.org/10.1515/9783110800524

MARMARIDOU, S. On the conceptual, cultural and discursive motivation of Greek pain lexicalizations. In: Cognitive Linguistics. Mouton de Gruyter. Volume 17-3, 2006.

NUNES, A.I.; TEIXEIRA, A. Estudo de emoção espontânea em Português Europeu utilizando Feeltrace - primeiras observações. Journal of Speech Sciences. Em: www.journalofspeechsciences.org/index.php/.../article/download/59/54, 2012.

REDDY, M. J. The conduit metaphor: a case of frame conflict in our language about language. In: ORTONY, A. Metaphor and thought. Cambridge University Press, 1984.

SANTOS, M. A. Dicionários de provérbios, Adágios, Ditados, Máximas, Aforismos e Frases Feitas, Porto, Porto Editora, 2000.

SILVA, A. S. da. O Mundo dos Sentidos em Português: Polissemia, Semântica e Cognição. Coimbra: Almedina, 2006.

SUÁREZ CUADROS, J. S. Análisis comparativo de las unidades fraseológicas que incluyen algún zoomorfismo en los idiomas Ucraniano y Español. Tese (Doutorado em Linguística). Estudios superiores de filología eslava y lingüística indoeuropea. Universidade de Granada, 2006. Disponível em: < http://hera.ugr.es/tesisugr/16540955.pdf >.

SWEETSER, E. From etymology to pragmatics: metaphorical and cultural aspects of semantic structure. Cambridge: University Press, 1990. crossref http://dx.doi.org/10.1017/CBO9780511620904

VILELA, M. Metáforas do nosso Tempo, Coimbra, Almedina, 2002.

XATARA, C. M.; RIVA, H. C.; RIOS, T. H. C. As dificuldades na tradução de idiomatismos. Cadernos de Tradução, Florianópolis, NUT, v. 8, 2002. 183-194 p.

ZULUAGA, A. Introducción al estudio de las expresiones fijas. Bern: 1980.

WIERZBICKA, A. Semantics: Primes and Universals. Oxford: Oxford University Press, 1996.

\section{Bibliografia}

BYBEE, J. Language, Usage and Cognition. Cambridge: Cambridge University Press., 2010, 262 pages. crossref $\underline{\mathrm{http}: / / \mathrm{dx} . \text { doi.org/10.1017/CBO9780511750526 }}$ 
CROFT, W.; CRUSE, A. D. Cognitive linguistics. Cambridge: University of Cambridge Press, 2009 [2004].

DAMÁSIO, A. R., O Erro de Descartes. Emoção, Razão e Cérebro Humano, $12^{\text {a }}$ edição, Lisboa, Publicações Europa-América, 1995 (col. Forum da Ciência, 29).

O Mistério da Consciência. São Paulo: Cia. Das Letras, 2000.

FAUCONNIER, G. Mappings in Thought and Language (Cambridge: Cambridge University Press, 1997.

GEERAERTS, D. Cognitive Linguistics: Basic Readings. Berlin/New York: Mouton de Gruyter, 2006.

GIBBS, R. W.; STEEN, G. What's Cognitive about Cognitive Linguistics, in Eugene H. Casad (ed.), in Cognitive Linguistics in the Redwoods: The Expansion of a New Paradigm in Linguistics, 27-53, Berlin: Mouton de Gruyter, 27-53, 1996.

HARKINS, J.; WIERZBICKA, A. Emotions in Crosslinguistic Perspective. Ed. by Jean Harkins, Anna Wierzbicka, 2001. cross ref $\mathrm{http}$ ://dx.dol.org/10.1515/9783110880168

KÖVECS, Z. Metonymy: developing a cognitive linguistic view. Cognitive Linguistics, 1998. 9-7, 37-77 p.

TURNER, M.; FAUCONNIER, G. Conceptual Integration and Formal Expression. Metaphor and Symbolic Activity, 10 (3), 1995. 183-204 p.

\section{Anexo 1}

\section{Expressões do PB}

1. Ser vivaz

2. Querer fuzilar os olhos de alguém

3. Ficar sem um pingo de sangue

4. Sacudir a poeira

5. Estar com o semblante carregado

6. Levantar o espírito

7. Estar embeiçado por alguém

8. Não estar para festas

9. Estar aos pés de alguém

10. Estar vendo tudo negro

11. Estar nublado

12. Ser louco por alguém

13. Ficar petrificada

14. Estar de quatro por alguém

15. Querer beber o sangue de alguém

16. Estar jurando pela pele de alguém 
17. Querer engolir alguém

18. Estar de boa data

19. Estar babando por alguém

20. Estar vendo o lado brilhante do quadro

21. Não querer ver alguém nem pintado de ouro

22. Estar com o sangue gelado nas veias

23. Estar com os cabelos arrepiados

24. Estar com o coração caído aos pés

25. Estar de má data

\section{Expressões do PE}

1. Cair a alma aos pés

2. Ferver-lhe o sangue na cabeça

3. Ficar sem pinga de sangue

4. Ter o fígado ao pé da boca

5. Ter o coração leve

6. Afogar-se em pouca água

7. Estar com o coração nas mãos

8. Ter o pavio curto

9. Ter os nervos à flor da pele

10. Beber os ares/ventos por alguém

11. Comer alguém com os olhos

12. Ter o coração pesado

13. Estar louco por alguém

14. Fazer tremer a barba a alguém

15. Ter um fraco por alguém

16. Cair o coração aos pés

17. Levar alguém no coração

18. Arrepiarem-se os cabelos

19. Com a carinha na água

20. Esfregar as mãos de contente

21. Não caber em si

22. Ter a morte no coração

23. Não caber o coração no peito

24. Beber lágrimas e gemidos

25. Sentir um nó na garganta

\section{Anexo 2}

1. Maria é vivaz.

[ ] Não conheço [ ] Uso esta expressão

2. Jéssica quer fuzilar os olhos de Armando.

[ ] Não conheço [ ] Uso esta expressão


3. Jorge ficou sem um pingo de sangue.

[ ] Não conheço [ ] Uso esta expressão

4. Suzana sacudiu a poeira.

[ ] Não conheço [ ] Uso esta expressão

5. Marisa está com o semblante carregado.

[ ] Não conheço [ ] Uso esta expressão

6. Mario levantou o espírito.

[ ] Não conheço [ ] Uso esta expressão

7. Gerson está embeiçado por Juliana.

[ ] Não conheço [ ] Uso esta expressão

8. Caio não está para festas.

[ ] Não conheço [ ] Uso esta expressão

9. Pedro está aos pés de Júlia.

[ ] Não conheço [] Uso esta expressão

10. Márcio está vendo tudo negro.

[ ] Não conheço [ ] Uso esta expressão

11. João está nublado.

[ ] Não conheço [ ] Uso esta expressão

12. Thiago é louco por Mara

[ ] Não conheço [ ] Uso esta expressão

13. Fátima ficou petrificada

[ ] Não conheço [ ] Uso esta expressão

14. Fernando está de quatro por Nara

[ ] Não conheço [ ] Uso esta expressão

15. João quer beber o sangue de Nina. 
[ ] Não conheço

[ ] Uso esta expressão

16. Júlia está jurando pela pele de Augusto.

[ ] Não conheço [ ] Uso esta expressão

17. Carlos quer engolir Maria.

[ ] Não conheço [ ] Uso esta expressão

18. Joana está de boa data

[ ] Não conheço [ ] Uso esta expressão

19. Cézar está babando por Carmen

[ ] Não conheço [ ] Uso esta expressão

20. João está vendo o lado brilhante do quadro

[ ] Não conheço [ ] Uso esta expressão

21. Maria não quer ver André nem pintado de ouro

[ ] Não conheço [] Uso esta expressão

22. Henrique está com sangue gelado nas veias

[ ] Não conheço [ ] Uso esta expressão

23. José está com os cabelos arrepiados

[ ] Não conheço [ ] Uso esta expressão

24. O coração de Fernando caiu aos pés

[ ] Não conheço [ ] Uso esta expressão

25. Pedro está de má data.

[ ] Não conheço [ ] Uso esta expressão

Artigo recebido em: 15.09.2014

Artigo aprovado em: 23.11.2014 